\title{
miR-146a and miR-146b promote proliferation, migration and invasion of follicular thyroid carcinoma via inhibition of ST8SIA4
}

\author{
Wei Ma ${ }^{1, *}$, Xuzi Zhao ${ }^{2, *}$, Leilei Liang ${ }^{1}$, Guangzhi Wang ${ }^{1}$, Yanyan Li $^{3}$, Xiaolong Miao ${ }^{1}$, \\ Yongfu Zhao ${ }^{1}$ \\ ${ }^{1}$ Department of General Surgery, The Second Hospital of Dalian Medical University, Dalian 116044, Liaoning Province, China \\ ${ }^{2}$ Hebei Medical University, Shijiazhuang 050017, Hebei Province, China \\ ${ }^{3}$ Changping Hospital of Integrated Chinese and Western Medicine, Beijing 102200, Beijing Province, China \\ *These authors contributed equally to this work
}

Correspondence to: Yongfu Zhao, email: zyf0386@sina.com

Keywords: follicular thyroid carcinoma, ST8SIA4, miR-146a, miR-146b, invasion

Received: September 07, $2016 \quad$ Accepted: February 21, $2017 \quad$ Published: March 03, 2017

Copyright: Ma et al. This is an open-access article distributed under the terms of the Creative Commons Attribution License (CC-BY), which permits unrestricted use, distribution, and reproduction in any medium, provided the original author and source are credited.

\section{ABSTRACT}

Follicular thyroid carcinoma (FTC) is a more aggressive form of thyroid cancer than the common papillary type. Alpha-2,8-sialyltransferase (ST8SIA) family members are expressed in various cancers and may be associated with FTC progression. In this study, we measured ST8SIA family expression in two FTC cell lines with different invasive potentials (FTC-133 and FTC-238) and Nthy-ori 3-1 cell lines, as well as FTC and normal thyroid tissues. ST8SIA4 was downregulated in the highly invasive FTC238 cells and FTC tissues. Additionally, ST8SIA4 inhibited proliferation, migration and invasion of FTC both in vitro and in vivo. miR-146a and miR-146b were previously shown to be upregulated in thyroid carcinoma, and bioinformatics analyses indicated that miR-146a and miR-146b inhibit ST8SIA4. We found that miR-146a and miR-146b were significantly upregulated in FTC and promoted tumour progression. Furthermore, ST8SIA4 restoration decreased the invasiveness of miR-146a/b-overexpressing FTC133 cells, and ST8SIA4 suppression reversed the effects of miR-146a/b inhibition in FTC-238 cells. We showed that miR-146a/b activated the PI3K-AKT-mTOR signalling pathway at least partially via suppression of ST8SIA4. Thus, our results demonstrate that miR-146a and miR-146b promote proliferation, migration and invasion of FTC via inhibition of ST8SIA4.

\section{INTRODUCTION}

Thyroid cancer is the most common endocrine neoplasm; it accounts for approximately $1 \%$ of all new malignant diseases, and its annual incidence is increasing worldwide [1]. Thyroid cancer is classified into four types: papillary ( $85 \%$ prevalence), follicular (10\% prevalence), medullary (3-4\% prevalence), and anaplastic thyroid cancer (1-2\% prevalence) $[2,3]$. Compared with papillary thyroid cancer (PTC), follicular thyroid cancer (FTC) is more aggressive and harder to diagnose [4]. Although most FTCs can be cured with surgery, the overall 10-year survival rate of FTC is lower than that of PTC [5]. Therefore, understanding the molecular mechanisms of FTC tumours is important for developing better diagnostic strategies and improving the therapeutic outcome of FTC.
Alpha-2,8-sialyltransferase (ST8SIA I-VI) mediates the transfer of sialic acid with an alpha 2,8-linkage [6]. Previous reports demonstrated that sialic acid is involved in various biological processes, including cell-cell adhesion, immune defence, tumour cell metastasis, and inflammation [7-10]. Increasing evidence has indicated that the ST8SIA family is associated with several human tumours. For example, ST8SIA4 is involved in the development of multidrug-resistant neoplasms in acute myeloid leukaemia cells [11]. In addition, ST8SIA2 promotes the invasive properties and chemosensitivity of human hepatocellular carcinoma [12]. However, whether the ST8SIA family has biological functions in FTC is poorly understood.

MicroRNAs (miRNAs) are a class of small noncoding RNAs that activate or inhibit target genes via 
translational repression or mRNA degradation [13]. miRNAs regulate many biological processes, such as the cell cycle, senescence, DNA repair and tumorigenesis $[14,15]$. Several reports have indicated that miRNAs are associated with thyroid cancer. For example, miR-34a promotes cell proliferation and inhibits apoptosis in PTC [16], whereas miR-200 inhibits epithelial-mesenchymal transition in anaplastic thyroid cancer [17]. However, whether miRNAs suppress ST8SIA and thereby affect the tumour characteristics of FTC remains unknown.

Activation of the PI3K-AKT-mTOR signalling pathway is implicated in the progression of thyroid cancer [18-20], and the PI3K-AKT signalling pathway is involved in the regulation of the sialyltransferase family [11]. Moreover, miRNAs have been reported to stimulate the PI3K-AKT-mTOR pathway in various diseases [21-23]. Therefore, we sought to determine whether PI3K-AKT-mTOR signalling is regulated by the ST8SIA family and miRNAs in FTC. This hypothesis has not been verified in previous studies.

In this study, we first investigated the expression and detailed role of the ST8SIA family variants in different invasive FTC cells. To elucidate the potential underlying mechanisms, we determined the role of miRNAs in the regulation of ST8SIA and FTC tumour characteristics. This work aimed to identify better preoperative markers for the diagnosis of FTC and new potential targets for its treatment.

\section{RESULTS}

\section{Within the ST8SIA family, ST8SIA4 and ST8SIA6 are significantly altered in FTC}

Real-time PCR analyses were performed to evaluate the expression of ST8SIA family members in FTC-238 cells (highly invasive), FTC-133 cells (poorly invasive) and Nthy-ori 3-1 cells (non-invasive). As shown in Figure $1 \mathrm{~A}$, the expression of ST8SIA4 was significantly downregulated in the FTC-238 cells compared with that of the FTC-133 and Nthy-ori 3-1 cells $(* p<0.05)$. Additionally, ST8SIA6 was significantly increased in the FTC-238 cells compared with that of the FTC-133 and Nthy-ori 3-1 cells $(* p<0.05)$. However, in all three cell lines, ST8SIA1 and ST8SIA5 did not show significant differences in expression, and ST8SIA2 and ST8SIA3 were not expressed $(* p>0.05)$ (Figure 1A).

To further verify these findings in cells, we examined the expression of the ST8SIA gene family in FTC and normal thyroid tissues. As expected, mRNA expression of ST8SIA4 was significantly lower in the FTC tissues than that of the normal thyroid tissues $(* p<0.05)$ (Figure 1B). However, no significant differences were found in the remaining ST8SIA family members in the tissue samples, whereas the expression of ST8SIA6 was significantly higher in the FTC tissues than that of the normal thyroid tissues $(* p<0.05)$.
We measured ST8SIA4 and ST8SIA6 protein levels in three cell lines using western blotting (Figure 1C). Similar to the mRNA levels, ST8SIA4 protein expression was lower in FTC-238 cells than that of the FTC-133 and Nthy-ori 3-1 cells, and ST8SIA6 protein expression was higher in the FTC-238 cells than that of the FTC-133 and Nthy-ori $3-1$ cells $(* p<0.05)$. These results indicate that ST8SIA4 and ST8SIA6 regulate FTC development.

\section{ST8SIA4 mediates the proliferation, migration and invasion of FTC cells both in vitro and in vivo}

Based on the significant alterations in ST8SIA4 and ST8SIA6 expression in the highly invasive FTC cells, we investigated whether these two ST8SIA members could affect the tumour properties of FTC cells. First, we transfected FTC-133 and FTC-238 cell lines with ST8SIA4specific shRNA or ST8SIA4 expression vectors to establish specific knockdown and overexpression cell lines, respectively $(* p<0.05$ ) (Figure $2 \mathrm{~A}, 2 \mathrm{~B})$. CCK-8 assays demonstrated that ST8SIA4 inhibition promoted FTC-133 cell proliferation, and ST8SIA4 overexpression significantly inhibited FTC-238 cell proliferation compared with that of the negative control cells $\left({ }^{*} p<0.05\right)$ (Figure $2 \mathrm{C}$ ). We also examined the colony formation capacity of the FTC-133 and FTC-238 cells. When ST8SIA4 was inhibited, the FTC133 cells formed more colonies than those of the control groups, and when ST8SIA4 was overexpressed, FTC-238 cells formed fewer colonies than those of the control groups $(* p<0.05)$ (Figure 2D). To assess the effect of ST8SIA4 on cellular motility, we conducted wound-healing assays and transwell assays to measure the migration and invasion of FTC-133 and FTC-238 cells. Cell migration and invasion were increased in the ST8SIA4-silenced FTC-133 cells and decreased in ST8SIA4-overexpressing FTC-238 cells $(* p<0.05)$ (Figure 2E, Supplementary Figure 1A). However, overexpression or inhibition of ST8SIA6 did not affect the proliferation, migration and invasion of FTC cells in vivo (data not shown); therefore, we focused on the role of ST8SIA4 in subsequent experiments.

We further assessed whether ectopic expression of ST8SIA4 inhibited tumour growth in vivo. A significant decrease in tumour weight was observed in ST8SIA4overexpressing tumours, and tumour weights were increased in the ST8SIA4-inhibited tumours compared with those of the controls $(* p<0.05)$ (Figure $2 \mathrm{~F})$. These data suggest that ST8SIA4 is an important negative regulator that mediates the proliferation, migration and invasion of FTC cells both in vitro and in vivo. These results prompted us to determine the molecular mechanisms underlying ST8SIA4 downregulation.

\section{$\mathrm{miR}-146 \mathrm{a} / \mathrm{b}$ can directly target and inhibit the expression of ST8SIA4}

miRNAs are potent gene regulators in a wide range of diseases. Because ST8SIA4 may be suppressed by 
miRNAs, we searched for potential targets of ST8SIA4 using the bioinformatics algorithms TargetScan (http:// www.targetscan.org), miRanda (http://www.microrna.org/ microrna/home.do) and mirbase (http://www.mirbase.org). We identified several miRNAs that may target ST8SIA4, including miR-146a, miR-146b, miR-664-3p, miR-216a$5 \mathrm{p}$, and miR-380-3p (data not shown). Notably, miR-146a and miR-146b were reportedly upregulated in thyroid cancer and promote the progression of thyroid cancer [24-26]. Figure 3A shows the sequence of the miR-146a and miR-146b seed regions and their 3 'UTR target sites

A

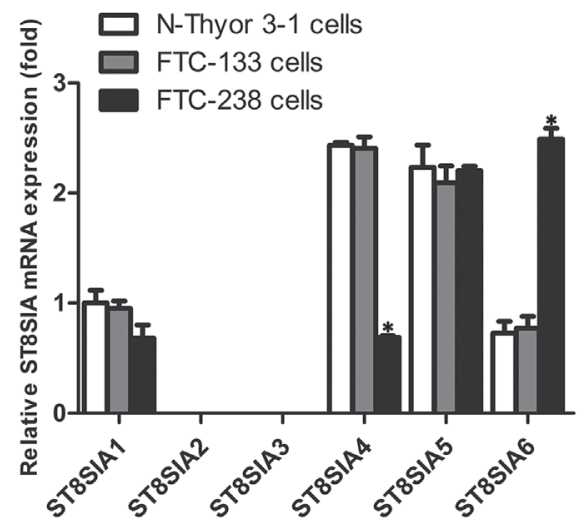

C

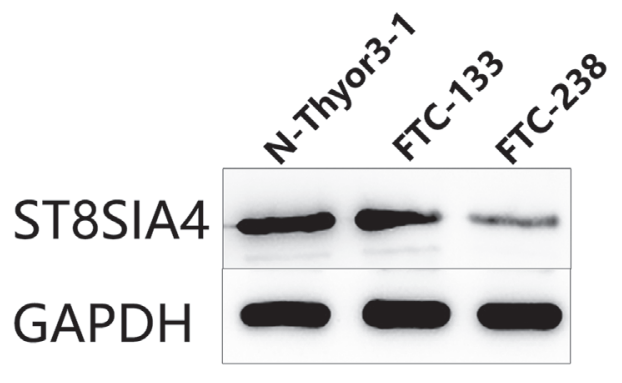

D

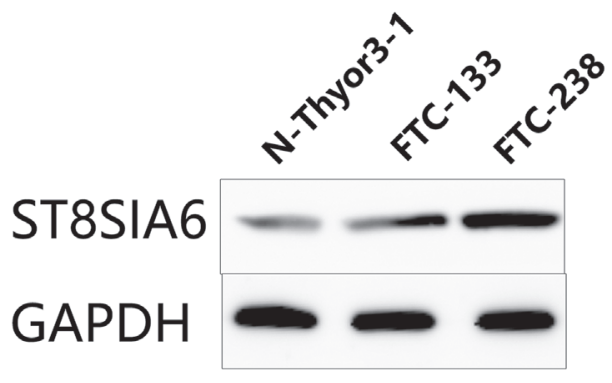

for ST8SIA4. To confirm that ST8SIA4 is a direct target of miR-146a and miR-146b in FTC, we transfected a luciferase fusion construct containing either the wild-type or mutated ST8SIA4 3'UTR into FTC-238 cells. As shown in Figure 3B, the luciferase activity of the wild-type (WT) 3'UTR reporter gene was significantly decreased, whereas the luciferase activity of the mutant reporter gene was not affected $(* p<0.05)$. These data indicate that $\mathrm{miR}-146 \mathrm{a} / \mathrm{b}$ binds to the 3'UTR of the ST8SIA4 gene.

To further explore the expression of $\mathrm{miR}-146 \mathrm{a} / \mathrm{b}$ in FTC, we examined the expression of miR-146a and

B
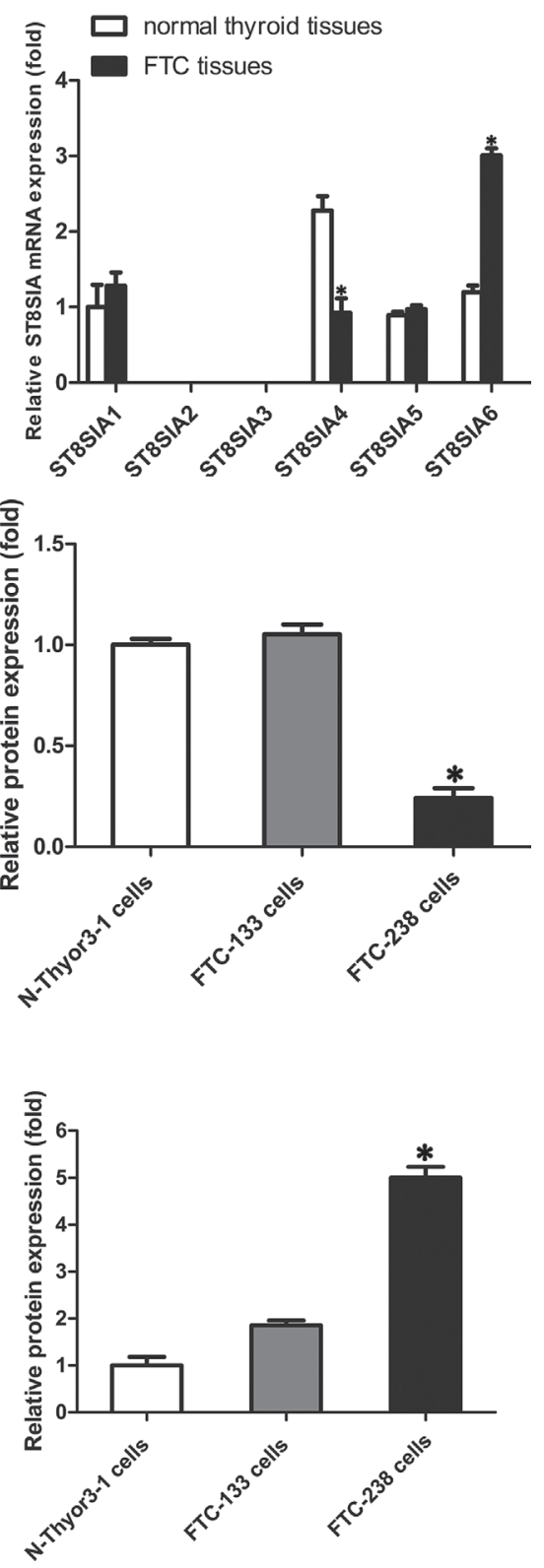

Figure 1: Within the ST8SIA family, ST8SIA4 and ST8SIA6 are significantly altered in FTC. (A) mRNA levels of the ST8SIA family members in the FTC-238, FTC-133, and Nthy-ori 3-1 cells ( ${ }^{*} p<0.05$ versus FTC-133 and Nthy-ori 3-1 cells). (B) mRNA levels of the ST8SIA family members in the tissue samples ( ${ }^{*} p<0.05$ versus normal thyroid tissue samples). (C) Protein levels of ST8SIA4 and ST8SIA6 in the FTC-238, FTC-133, and Nthy-ori 3-1 cells ( ${ }^{*} p<0.05$ versus FTC-133 and Nthy-ori 3-1 cells). GAPDH served as a control. Data are shown as the mean $\pm \mathrm{SD}$ of three repeated experiments. 


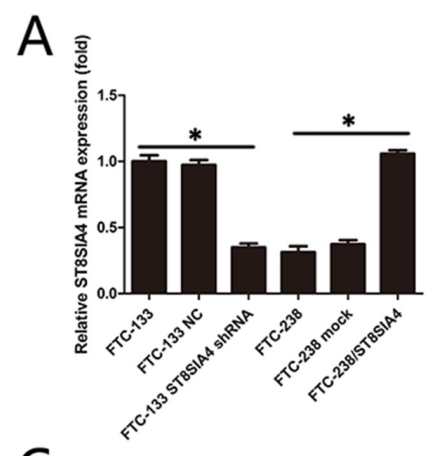

C

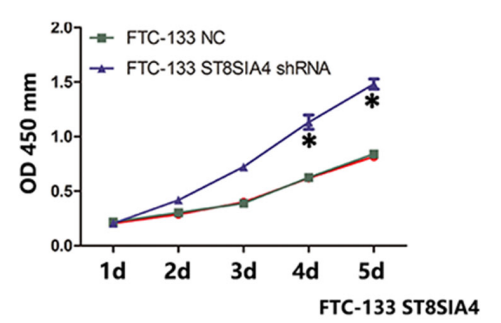

D
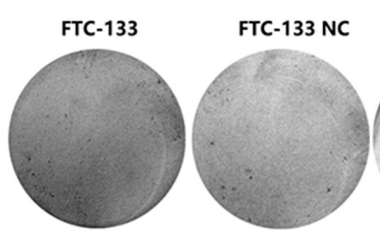

E
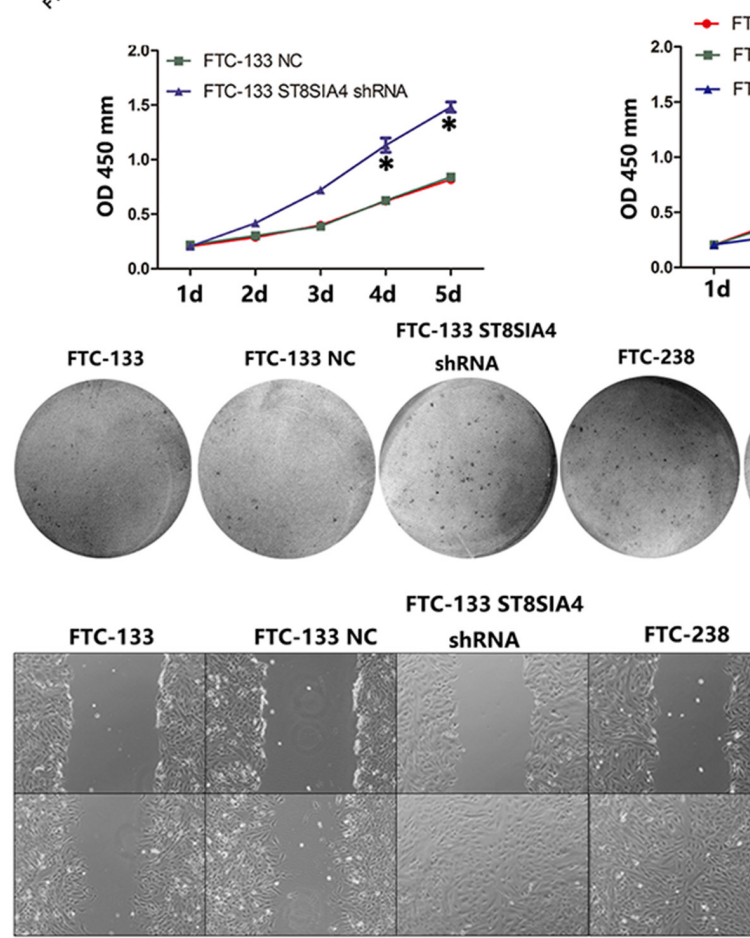

- FTC-238

B

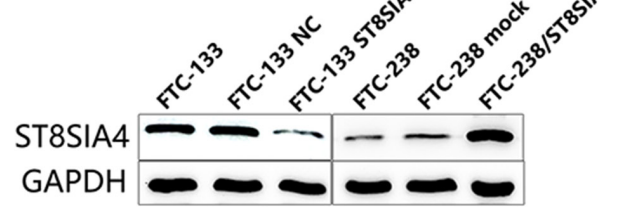

FTC-133 ST8SIA4

\section{Oh}

$24 \mathrm{~h}$

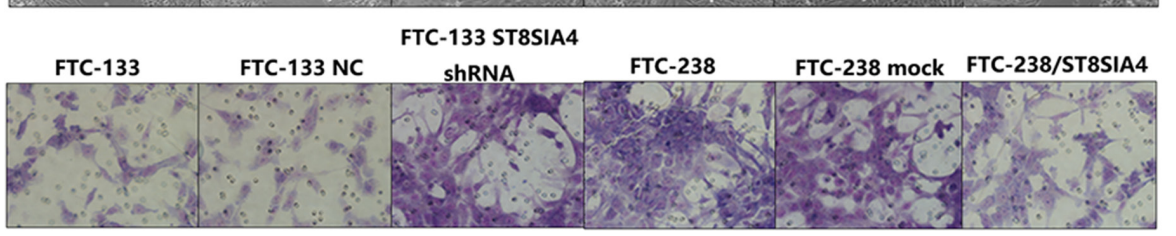

FTC-133

F

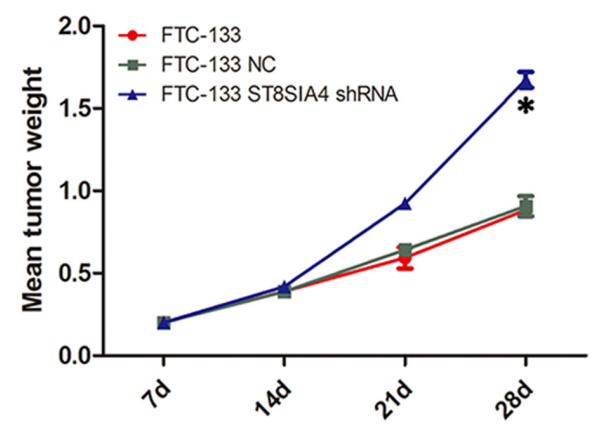

FTC-238
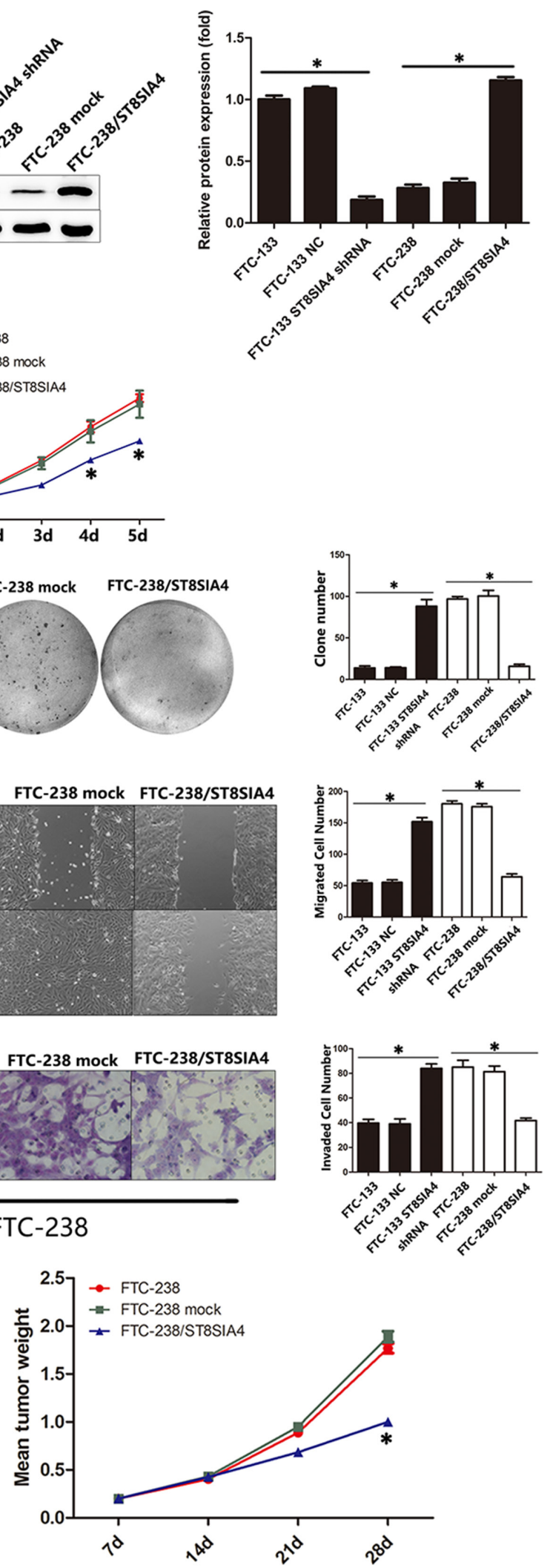

Figure 2: ST8SIA4 mediates the proliferation, migration and invasion of FTC cells both in vitro and in vivo. FTC-133 and FTC-238 cell lines were transfected with ST8SIA4-specific shRNA or ST8SIA4 expression vector to establish the ST8SIA4-specific knockdown and overexpressing cells. (A-B) mRNA and protein expression of ST8SIA4 in the transfected cells. (C) Cell proliferation in the transfected cells. (D) Number of colonies formed in the transfected cells and NC cells. (E) Number of cells that migrated to the wound or invaded through the filter. (F) Transfected cells were injected subcutaneously into nude mice. The chart indicates the mean weight of the tumours after transplantation. See also Supplementary Figure 1A. Data are shown as the mean $\pm \mathrm{SD}$ of three repeated experiments $\left({ }^{*} p<0.05\right)$. 
miR-146b in cells and tissues (Figure 3C). As shown in Figure 3C, miR-146a and miR-146b levels increased in the FTC-238 cells compared with those of the FTC-133 or Nthy-ori 3-1 cells $(* p<0.05)$. In addition, the expression of miR-146a and miR-146b was higher in the FTC tissues than that of the normal thyroid tissues $\left({ }^{\#} p<0.05\right)$ (Figure 3C). We further examined the expression of miR146a and miR-146b in FTC-133 cells transfected with miR-146a or miR-146b mimics and the FTC-238 cells transfected with miR-146a or miR-146b antagomirs (Figure 3D).

The ST8SIA4 protein levels were downregulated in the FTC-133 cells transfected with miR-146a and/or miR-146b mimics compared with those of the NC cells $(* p<0.05)$ (Figure 3E). Moreover, the ST8SIA4 protein levels were increased in the FTC-238 cells transfected with miR-146a and/or miR-146b antagomirs compared with those of the NC cells $(* p<0.05)$ (Figure 3F). Taken together, these results demonstrate that miR-146a and miR-146b are negative regulators of ST8SIA4 in FTC.

\section{$\mathrm{miR}-146 \mathrm{a} / \mathrm{b}$ regulates the proliferation, migration and invasion of FTC-133 cells and FTC-238 cells both in vitro and in vivo}

To further elucidate the role of miR-146a/b in FTC, we investigated the proliferation, migration and invasion of miR-146a/b-silenced FTC-238 cells or miR-146a/boverexpressing FTC-133 cells. CCK-8 assays demonstrated that miR-146a and/or miR-146b overexpression significantly promoted FTC-133 cell proliferation relative to that of the NC cells, whereas miR-146a and/or miR-146b inhibition reduced FTC-238 cell proliferation compared with that of the NC cells ( $\left.{ }^{*} p<0.05,{ }^{*} p<0.05\right)$ (Figure 4A). The colony formation assays indicated that FTC-133 cells overexpressing miR-146a and/or miR-146b formed more colonies than those of the control groups, and miR146a- and/or miR-146b-inhibited FTC-238 cells formed fewer colonies than those of the control groups $(* p<0.05$, ${ }^{\#} p<0.05$ ) (Figure 4B). As shown in Figure 4C, miR-146a and/or miR-146b overexpression increased the migration and invasion of FTC-133 cells, whereas the inhibition of miR-146a and/or miR-146b reduced the migration and invasion of FTC-238 cells ( $\left.{ }^{*} p<0.05,{ }^{*} p<0.05\right)$.

Consistent with the results of the above assays, the nude mouse xenograft model showed an increase in tumour weight relative to that of the NC cells when the FTC-133 cells were transfected with miR-146a and/ or $146 \mathrm{~b}$ mimics $(* p<0.05)$ (Figure 4D) and a decrease in tumour weight relative to the NC cells when the FTC238 cells were transfected with miR-146a and/or miR$146 \mathrm{~b}$ antagomirs $\left({ }^{\#} p<0.05\right)$ (Figure 4E, Supplementary Figure 1B). These data suggest that miR-146a/b promotes the proliferation, migration and invasion of FTC both in vitro and in vivo.

\section{ST8SIA4 suppresses the effects of miR-146a/b in FTC}

To investigate whether the effects of $\mathrm{miR}-146 \mathrm{a} / \mathrm{b}$ in FTC are mediated by ST8SIA4, we rescued ST8SIA4 expression in the miR-146a/b-overexpressing FTC-133 cells and suppressed ST8SIA4 expression in the miR-146a/ b-inhibited FTC-238 cells. As shown in Figure 5A-5D, ST8SIA4 restoration decreased the proliferation, migration and invasion of miR-146a/b-overexpressing FTC-133 cells and partially decreased the migration and invasion capacity of these cells compared with those of the NC cells $(* p<0.05)$. Furthermore, ST8SIA4 suppression partially increased the proliferation, migration and invasion of miR-146a/b-inhibited FTC-238 cells compared with those of the $\mathrm{NC}$ cells $(* p<0.05)$. Importantly, the FTC-133 cells transfected with the ST8SIA4 expression vector reversed the tumour growth induced by miR$146 \mathrm{a} / \mathrm{b}$ in vivo, whereas the FTC-238 cells transfected with the ST8SIA4-specific shRNA reversed the tumour growth inhibitory effect of $\mathrm{miR}-146 \mathrm{a} / \mathrm{b}$ inhibition in vivo (Figure 5E, Supplementary Figure 1C). These results suggest that ST8SIA4 is an important participant in the regulation of $\mathrm{miR}-146 \mathrm{a} / \mathrm{b}$ and suppresses FTC proliferation, migration and invasion.

\section{$\mathrm{miR}-146 \mathrm{a} / \mathrm{b}$ is inversely correlated with ST8SIA4 in FTC and associated with the activation of the PI3K-AKT-mTOR signalling pathway}

Previous studies have shown that the PI3KAKT-mTOR signalling pathway is regulated by the sialyltransferase family and miRNAs in various cancers, including thyroid cancer $[11,18-23]$. Therefore, we evaluated the ability of miR-146a/b and ST8SIA4 to regulate the PI3K-AKT-mTOR signalling pathway both in vitro and in vivo. As shown in Figure 6, PI3K p110 $\alpha$, phosphorylated Akt (p-Akt T380, p-Akt S473) and phosphorylated mTOR (p-mTOR) were increased in miR-146a/b-overexpressing FTC-133 cells and partially decreased after ST8SIA4 restoration $(* p<0.05$, ${ }^{\#} p<0.05$ ) (Figure 6A). Furthermore, ST8SIA4 suppression partially increased the levels of PI3K p110 $\alpha$, p-Akt T380, p-Akt S473 and p-mTOR in miR$146 \mathrm{a} / \mathrm{b}$-inhibited FTC-238 cells compared with those of the NC cells $\left(* p<0.05,{ }^{*} p<0.05\right.$ ) (Figure 6B). The protein levels of PI3K p110 $\alpha$, p-Akt T380, p-Akt S473, p-mTOR and ST8SIA4 were decreased in the xenograft tumour tissues transfected with miR-146a/b antagomirs $(* p<0.05)$ (Figure 6C). Additionally, total AKT and $\mathrm{mTOR}$ protein levels did not change in the three experiments $\left(* p>0.05,{ }^{*} p<0.05\right)$ (Figure 6A-6C). These results suggested that $\mathrm{miR}-146 \mathrm{a} / \mathrm{b}$ activates the PI3K-AKT-mTOR signalling pathway, which is suppressed by ST8SIA4. 
A

ST8SIA4 3' ACUCUUGACAUGAUG- ACACUU || ||||||$|:|||||$

hsa-miR-146a $5^{\prime}$ UGAGAACUGAAUUCCAUGGGUU

ST8SIA4 3' ACUCUUGACAUGAUGACACUUA

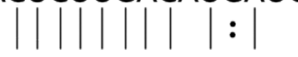

hsa-miR-146b 5' UGAGAACUGAAUUCCAUGGGUU

C

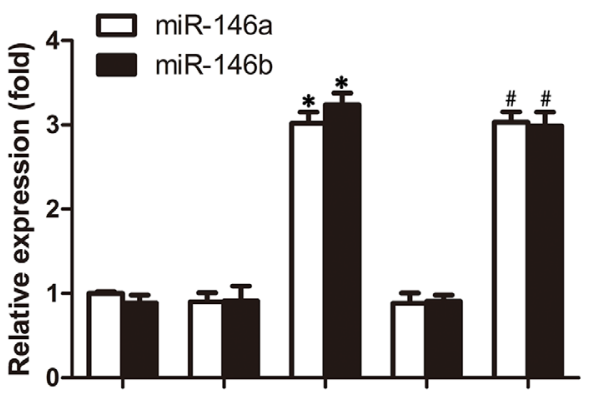

E<smiles>CCCCCCCCCC</smiles>

ST8SIA4 GAPDH
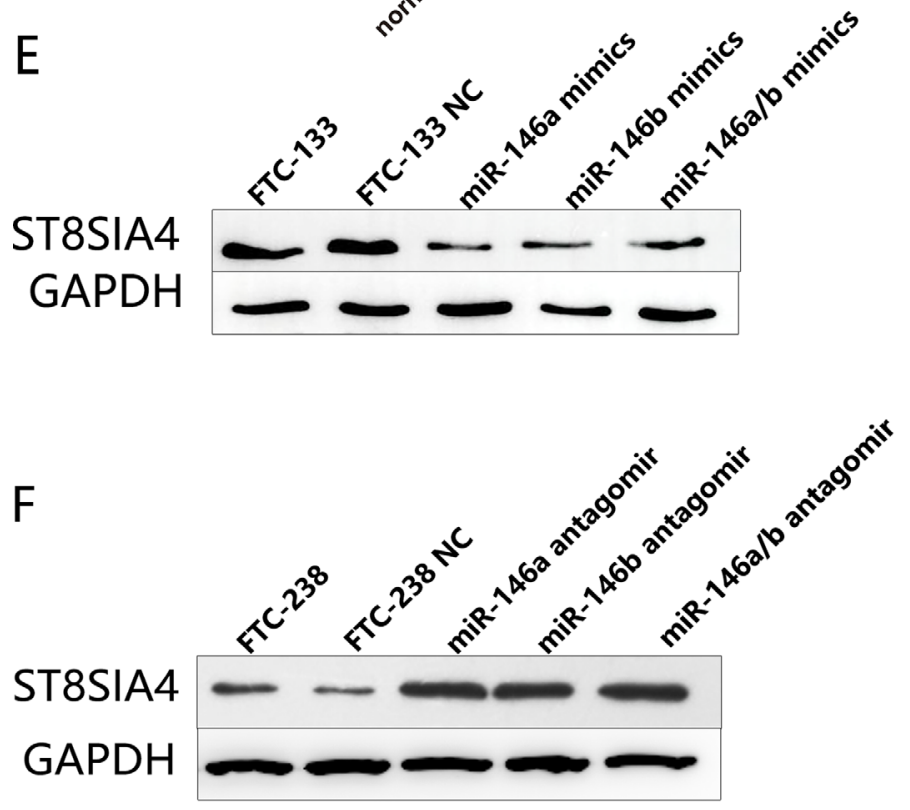

B

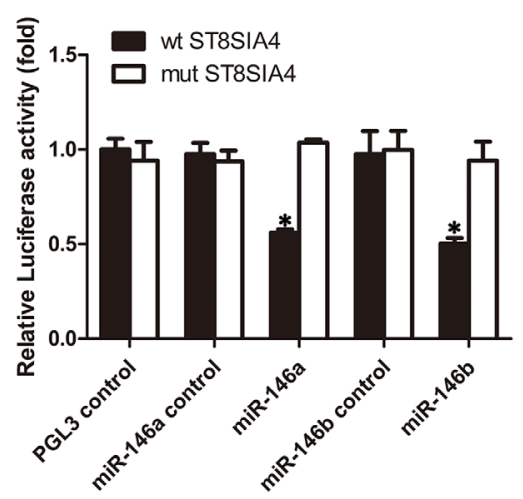

D
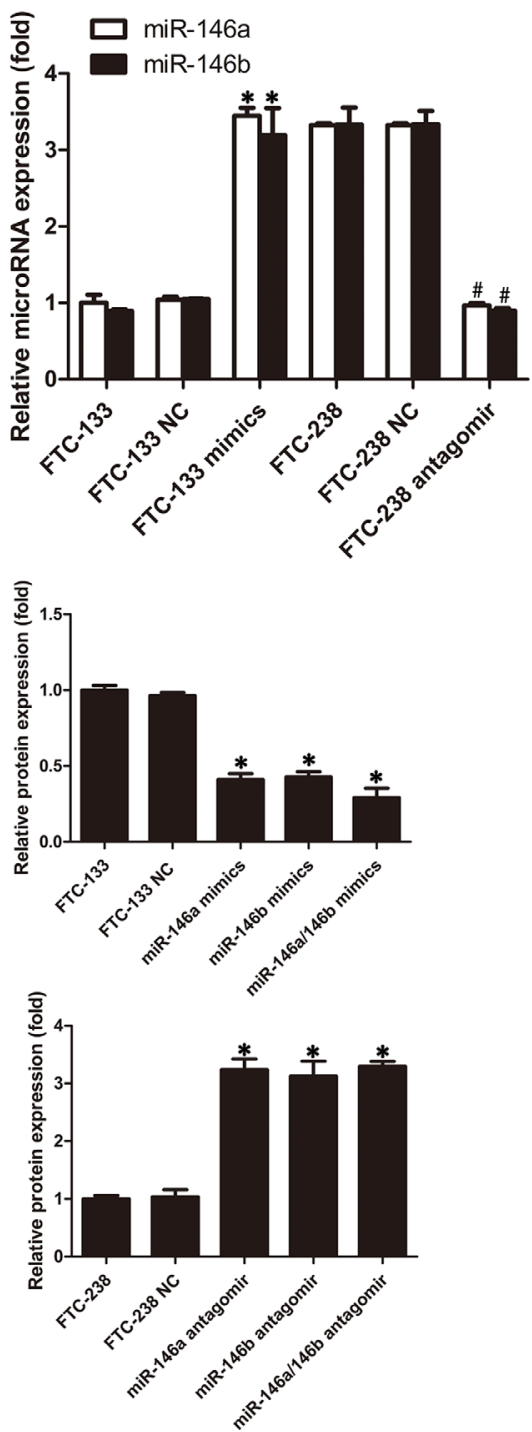

Figure 3: miR-146a/b can directly target and inhibit the expression of ST8SIA4. (A) Schematic representation of the sequence alignment of miR-146a and miR-146b and their complementary 3'UTR binding sites for ST8SIA4. (B) FTC-238 cells were transfected with $3^{\prime}$ UTR-wt or 3'UTR-mut and with miR-146a/b mimics or miR-146a/b control as indicated. (C) Expression levels of miR-146a and miR-146b in the FTC-238 cells, FTC-133 cells, Nthy-ori 3-1 cells and tissue samples. miR-146a and miR-146b expression was normalized using U6 expression $\left({ }^{*} p<0.05\right.$ versus Nthy-ori 3-1 and FTC-133 cells; ${ }^{*} p<0.05$ versus normal thyroid tissue samples). (D) Expression of miR-146a and miR-146b in the FTC-133 cells transfected with the mimics or in the FTC-238 cells transfected with the antagomirs $\left({ }^{*} p<0.05\right.$ versus FTC-133 and FTC-133 NC cells; ${ }^{*} p<0.05$ versus FTC-238 and FTC-238 NC cells). (E) Protein levels of ST8SIA4 in the FTC-133 cells transfected with miR-146a and/or miR-146b mimics ( ${ }^{*} p<0.05$ versus NC cells). (F) Protein levels of ST8SIA4 in the FTC-238 cells transfected with miR-146a and/or miR-146b antagomirs ( ${ }^{*} p<0.05$ versus NC cells). Data are shown as the mean $\pm \mathrm{SD}$ of three repeated experiments. 
A

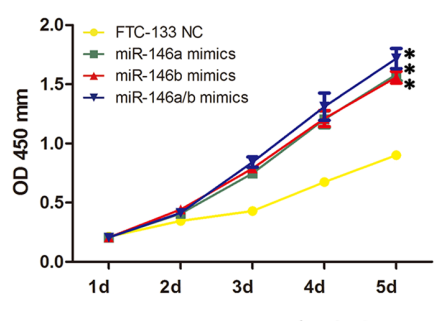

B

$B$
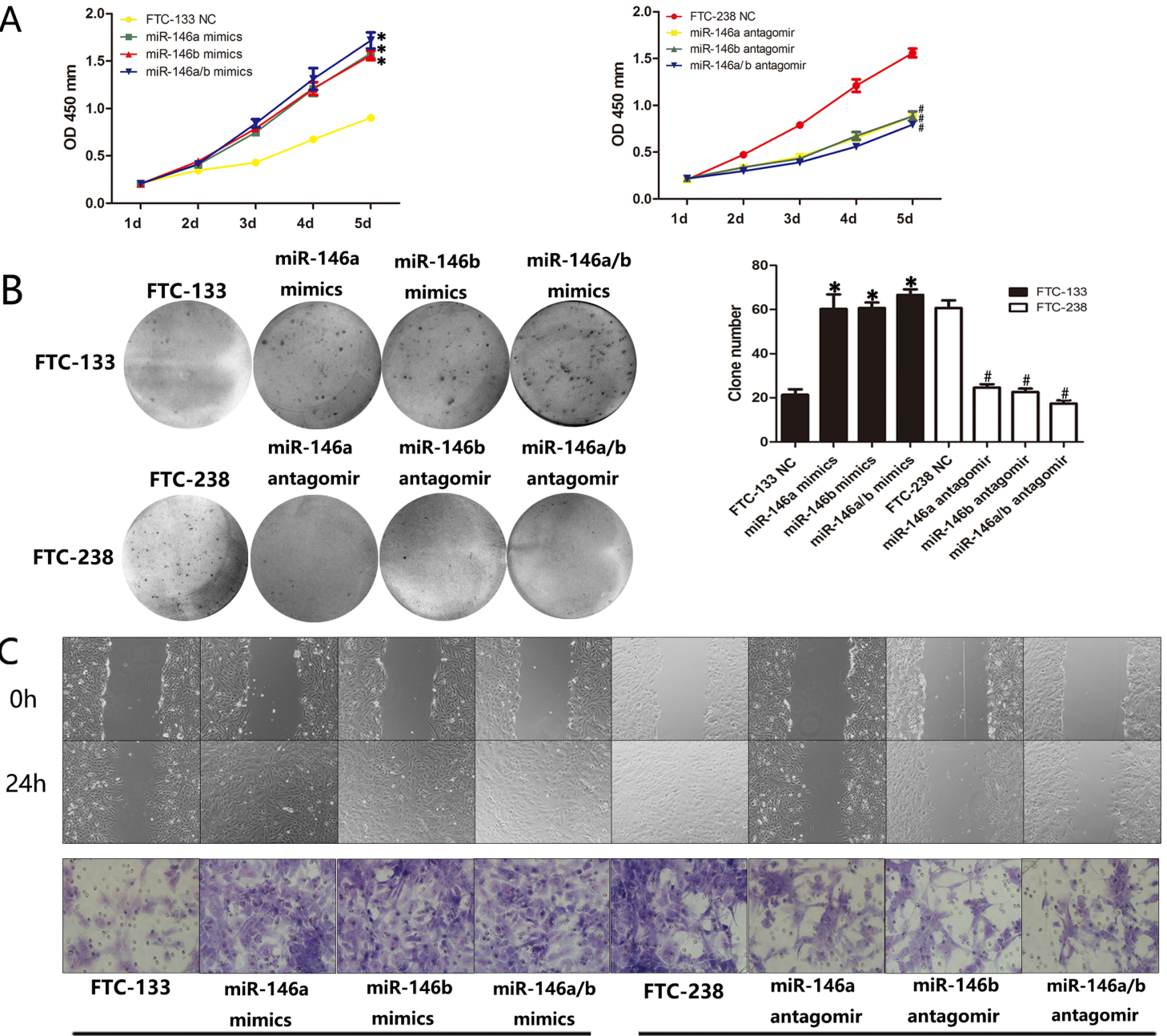

FTC-133
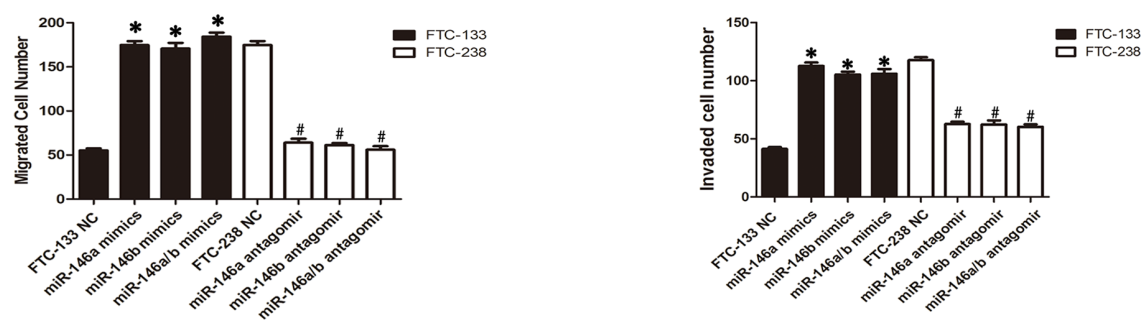

D
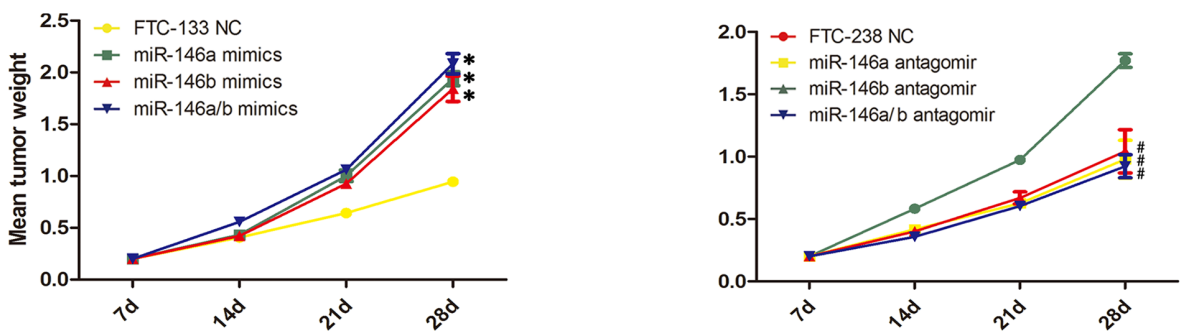

Figure 4: $\mathrm{miR}-146 \mathrm{a} / \mathrm{b}$ regulates the proliferation, migration and invasion of $\mathrm{FTC}-133$ cells and FTC-238 cells both in vitro and in vivo. FTC-133 cells transfected with miR-146a and/or miR-146b mimics and FTC-238 cells transfected with miR-146a and/or miR-146b antagomirs. (A) Cell proliferation of the transfected cells and NC cells. (B) Number of colonies formed in the transfected cells and NC cells. (C) Number of cells that migrated to the wound or invaded through the filter. (D) Transfected cells were injected subcutaneously into nude mice. The weight of the tumours after transplantation. See also Supplementary Figure 1B. Data are shown as the mean \pm SD of three repeated experiments ( ${ }^{*} p<0.05$ versus FTC-133 NC cells; ${ }^{*} p<0.05$ versus FTC-238 NC cells). 
A
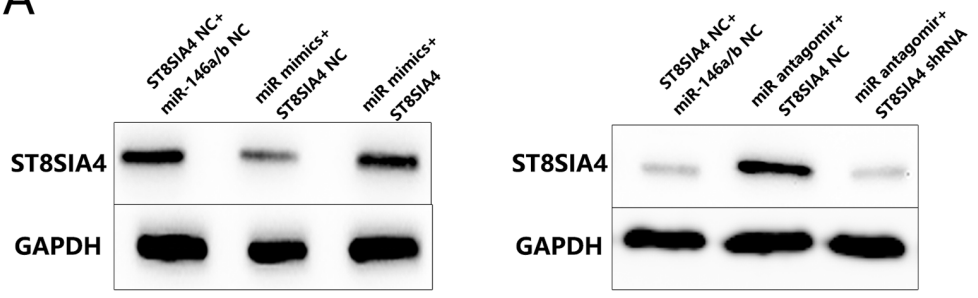

B
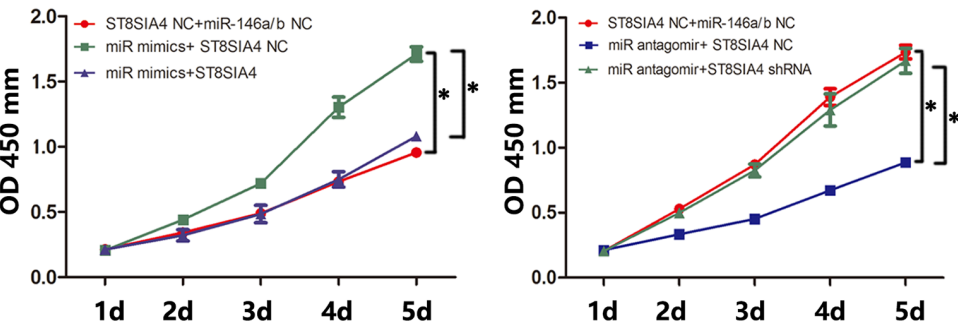

C
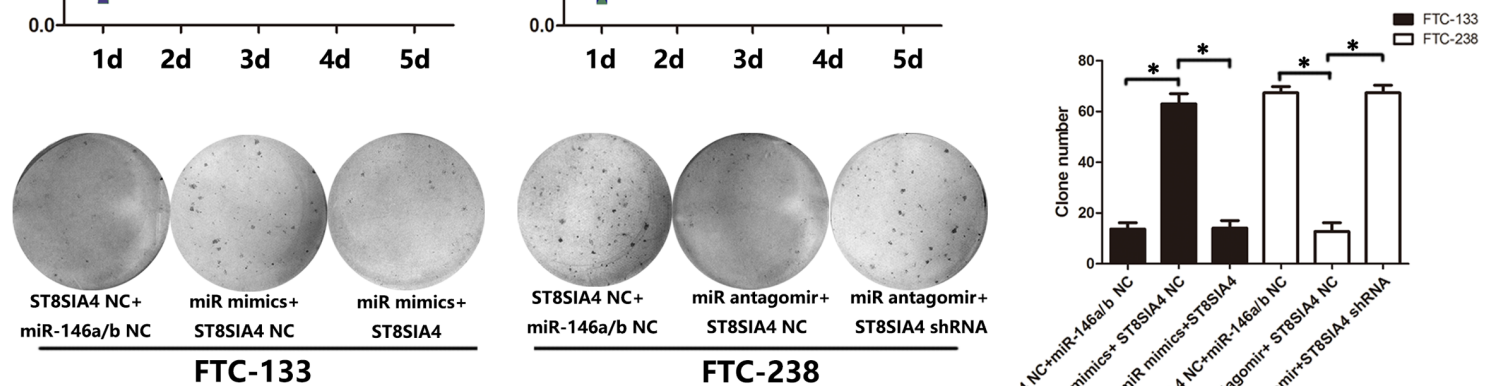

FTC-133

FTC-238

D

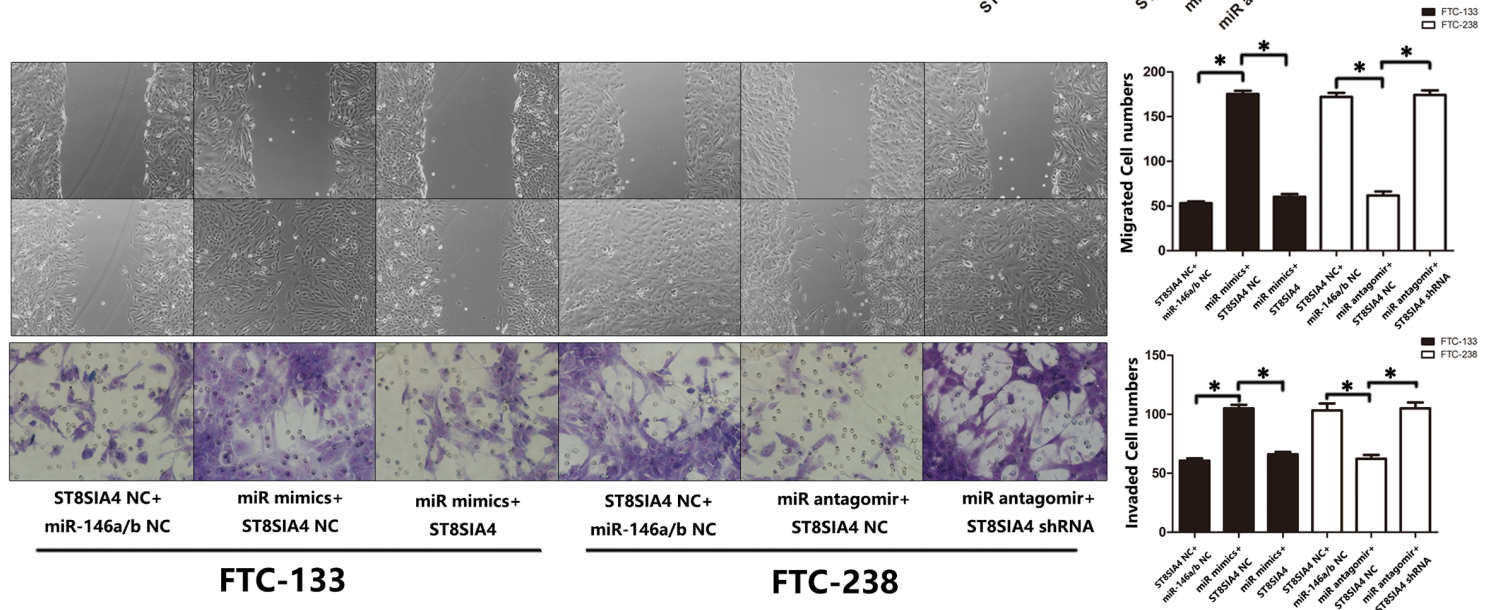

$E$
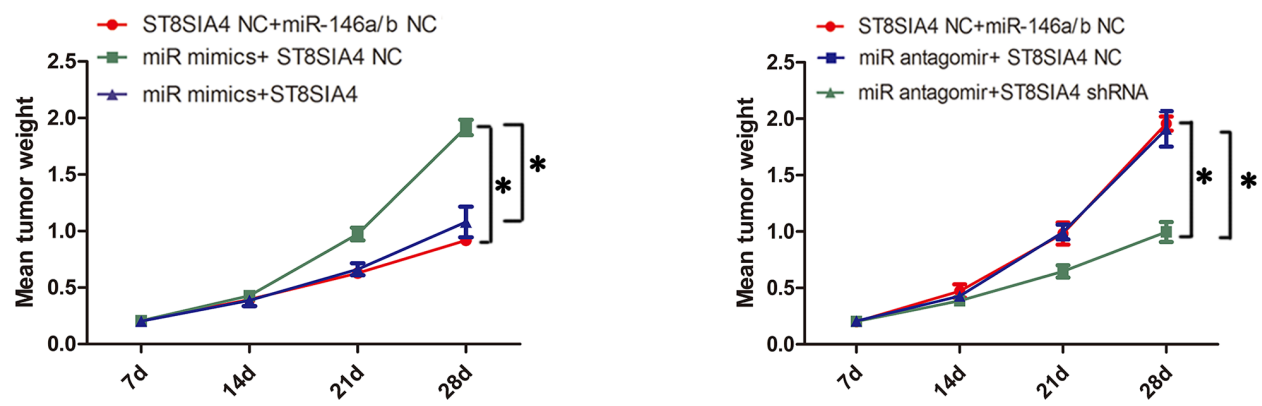

Figure 5: ST8SIA4 suppresses the effects of miR-146a/b in FTC. FTC-133 cells were co-transfected with miR NC and ST8SIA4 NC, miR-146a/b mimics and ST8SIA4 NC, or miR-146a/b mimics and ST8SIA4 shRNA. FTC-238 cells were co-transfected with miR NC and ST8SIA4 NC, miR-146a/b antagomirs and ST8SIA4 NC, or miR-146a/b antagomirs and ST8SIA4. (A) Protein levels of ST8SIA4 in the transfected cells. (B) Cell proliferation of the transfected cells and NC cells. (C) Number of colonies formed in the transfected cells and NC cells. (D) Number of cells that migrated to the wound or invaded through the filter. (E) Weight of the tumours after transplantation. See also Supplementary Figure 1C. Data are shown as the mean \pm SD of three repeated experiments $\left({ }^{*} p<0.05\right)$. 

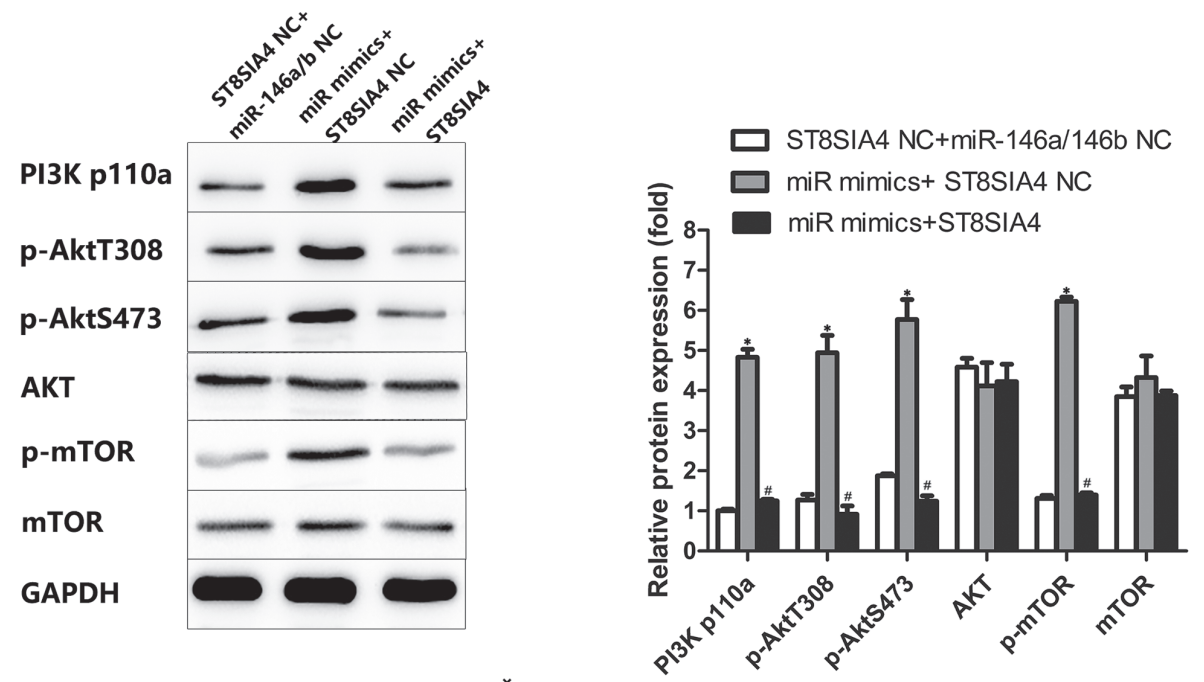

B
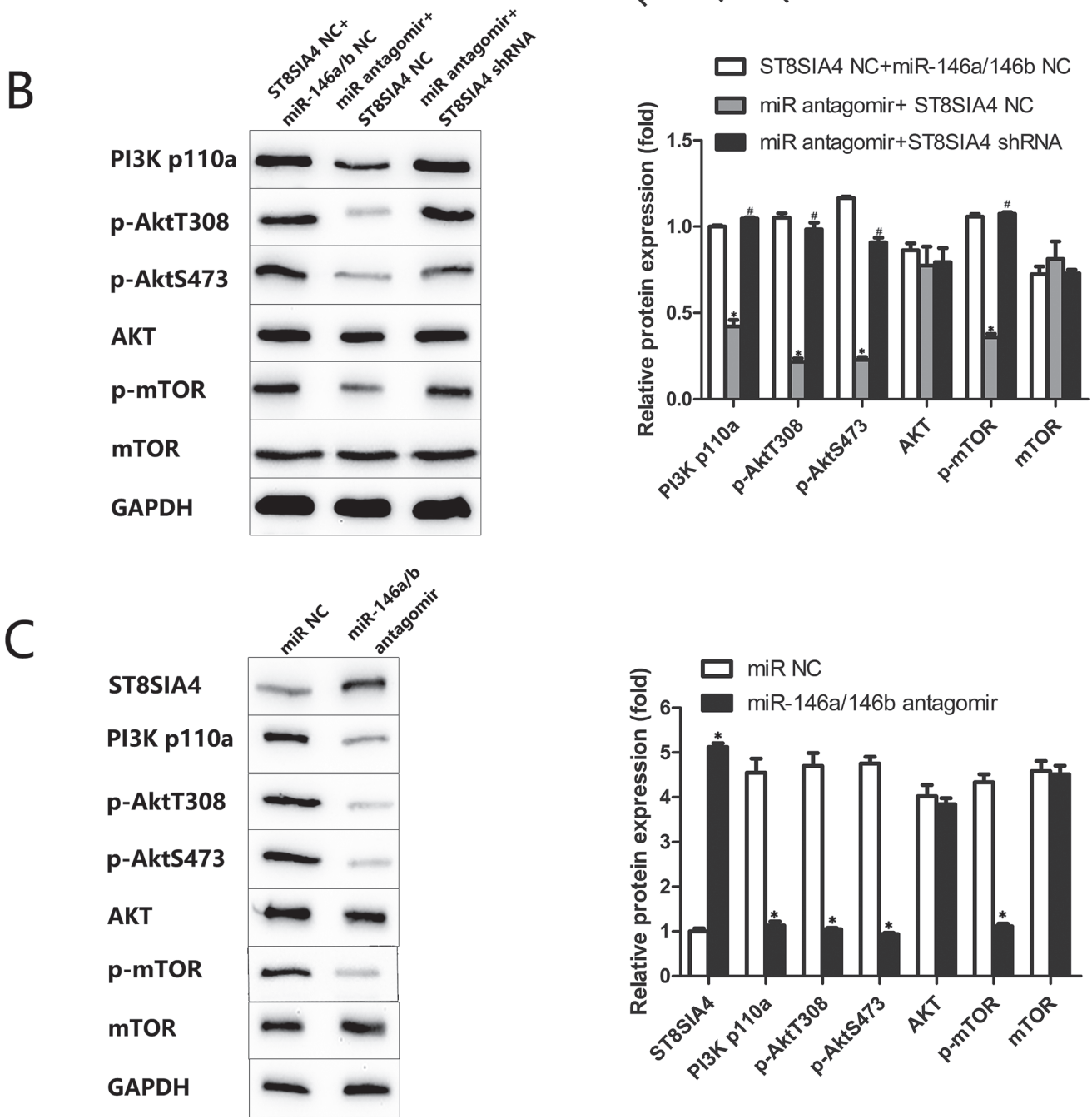

Figure 6: miR-146a/b is inversely correlated with ST8SIA4 in FTC and associated with the activation of the PI3KAKT-mTOR signalling pathway. FTC-133 cells were co-transfected with miR NC and ST8SIA4 NC, miR-146a/b mimics and ST8SIA4 NC, or miR-146a/b mimics and ST8SIA4 shRNA. FTC-238 cells were co-transfected with miR NC and ST8SIA4 NC, miR146a/b antagomirs and ST8SIA4 NC, or miR-146a/b antagomirs and ST8SIA4. (A) Protein levels of PI3K p110 $\alpha$, p-Akt T380, p-Akt S473, AKT, p-mTOR and mTOR in the transfected FTC-133 cells $\left({ }^{*} p<0.05\right.$ versus NC cells; ${ }^{*} p<0.05$ versus miR-146a/b mimics and ST8SIA4 NC). (B) Protein levels of the above molecular markers in the transfected FTC-238 cells $\left({ }^{*} p<0.05\right.$ versus NC cells; ${ }^{*} p<0.05$ versus miR146a/b antagomirs and ST8SIA4 NC). (C) Protein levels of the above molecular markers and ST8SIA4 in the xenograft tumour tissue with $\mathrm{miR}-146 \mathrm{a} / \mathrm{b}$ antagomirs $\left({ }^{*} p<0.05\right.$ versus $\mathrm{NC}$ cells). 


\section{DISCUSSION}

FTC is the second most common malignancy originating from thyroid follicular cells. In this study, we provided the first evidence of the following four findings: (1) ST8SIA4 expression is lower in FTC tissues and cultured highly invasive FTC cells than that in normal tissues and cells and suppressed the proliferation, migration and invasion of FTC both in vitro and in vivo; (2) $\mathrm{miR}-146 \mathrm{a} / \mathrm{b}$ is significantly upregulated in the highly invasive FTC cells, which are direct targets of ST8SIA4; (3) $\mathrm{miR}-146 \mathrm{a} / \mathrm{b}$ inhibition attenuates the proliferation, migration and invasion of FTC by repressing ST8SIA4 both in vitro and in vivo; and (4) miR-146a/b suppresses ST8SIA4 in FTC partly via regulation of the PI3K/AKT/ mTOR signalling pathway. To the best of our knowledge, this is the first study to explore the inhibitory role of ST8SIA4 in regulating the tumour characteristics of FTC and the relationship of ST8SIA4 and miRNAs in FTC.

Sialyltransferases catalyse the transfer of sialic acid to proteins and lipids and participate in the synthesis of the core structure of oligosaccharides [27]. Native sialylation is critical for the function of therapeutic proteins because it affects the physical, chemical and immunogenic properties of glycoproteins [28]. Importantly, altered sialylation is a hallmark of cancer, and abnormally expressed sialylated glycans are biomarkers of cancer [29]. In this study, we found that the expression of ST8SIA4, a type of sialyltransferase, was lower in highly invasive FTC cells (FTC-238 cells) than that in minimally invasive FTC cells (FTC-133 cells). Then, we performed functional analyses and found that ST8SIA4 downregulation may contribute to the aggressive properties of FTC. These findings prompted us to further explore the detailed mechanisms underlying ST8SIA4 downregulation in FTC.

miRNAs are potent gene regulators that have been implicated in multiple pathophysiological processes and may play a crucial role in the progression of thyroid cancer [17, 30-32]. Thus, we sought to determine whether ST8SIA4 expression is controlled by miRNAs. Bioinformatics analysis and luciferase activity assays confirmed miR-146/b binding to the $3^{\prime}$ UTR of the ST8SIA4 mRNA. According to these results, we suggest that miR$146 \mathrm{a}$ and miR-146b are potential regulators of ST8SIA4.

Previous reports have shown that miR-146a and miR$146 \mathrm{~b}$ are positively regulated in thyroid cancer $[24,26,33]$. We found that miR-146a and miR-146b promoted the tumour characteristics of FTC both in vivo and in vitro. Importantly, our gain- and loss-of-function analyses showed that the effects of miR-146a/b knockdown in the FTC-238 cells were reversed by inhibition of ST8SIA4 and vice versa. Thus, miR-146a/b suppresses ST8SIA4 in FTC, which consequently promotes the proliferation, migration and invasion of FTC cells.

Ma et al. found that the PI3K-AKT pathway is located downstream of ST8SIA4 [11]. In this study, we further verified that the PI3K-Akt-mTOR signalling pathway is involved in the regulation of $\mathrm{miR}-146 \mathrm{a} / \mathrm{b}$ and ST8SIA4 in FTC. In addition, the expression of the PI3KAKT-mTOR pathway mimics the expression of miR$146 \mathrm{a} / \mathrm{b}$ in FTC-238 cells and FTC-133 cells, which are negatively regulated by ST8SIA4. Therefore, we suggest that PI3K-Akt-mTOR pathway activation is correlated with the tumour properties of FTC.

A single miRNA may target several transcripts [34]; therefore, additional miR-146a and miR-146b targets may be involved in regulating the tumour characteristics of FTC. PTTG1, which is targeted by miR-146a and miR$146 \mathrm{~b}$, is also regulates thyroid cancer [35]. However, PTTG1 expression was not significantly altered in FTC133 and FTC-238 cells when miR-146a and miR-146b were inhibited (data not shown). PTEN, another target of miR-146a and miR-146b, may also suppress thyroid cancer [36-38]. However, whether this gene participates in FTC progression requires further investigation.

In this study, we found that miR-146a and miR$146 \mathrm{~b}$ promote the proliferation, migration and invasion of FTC via inhibition of ST8SIA4 and regulation of the PI3K-AKT-mTOR signalling pathway. Our findings further elucidate the molecular mechanisms underlying FTC progression and provide candidate targets for the prevention and treatment of FTC. Although additional studies are needed to explore these therapeutic targets, we confirmed that ST8SIA4 and miR-146a/b play key roles in FTC.

\section{MATERIALS AND METHODS}

\section{Cell culture}

Human thyroid cell lines (FTC-133, FTC-238, and Nthy-ori 3-1) were purchased from Jennio Biotech Co. (Guangdong, Guangzhou, China). The cells were cultured in Dulbecco's modified Eagle's medium (DMEM) (Gibco, Grand Island, NY, USA) supplemented with antibiotics (100 U/ml 1×penicillin/streptomycin, Gibco) and 10\% heat-inactivated foetal bovine serum (Gibco). The cells were incubated at $37^{\circ} \mathrm{C}$ in a humidified atmosphere containing $5 \% \mathrm{CO}_{2}$.

\section{Tissue samples}

After informed consent was obtained, resected thyroid cancer tissue samples were collected from 110 patients diagnosed with FTC (48 men and 62 women; median age, 58; range, 37-76). Normal thyroid tissue samples were collected from 110 patients diagnosed with thyroid nodules (41 men and 69 women; median age, 41; range, 24-69). All patients underwent surgical resection between January 2012 and June 2015 at the Second Affiliated Hospital of Dalian Medical University. The investigation and informed consent protocol were 
certified and approved by the Ethics Committee of the Second Affiliated Hospital of Dalian Medical University. The pathological diagnosis of the collected samples was confirmed according to the Union for International Cancer Control (UICC) criteria. The clinicopathological data were extracted from the patient's medical records. None of the patients had received chemotherapy or radiation therapy. The collected tissues were snap-frozen in liquid nitrogen and stored at $-80^{\circ} \mathrm{C}$ until use.

\section{RNA isolation and real-time PCR}

Total RNA was isolated from the cell lines using an RNeasy Mini Kit (Qiagen, Valencia, CA), and cDNA was synthesized using a QuantiTect Reverse Transcription Kit (Qiagen, Valencia, CA) according to the manufacturers' protocol. For the mRNA expression analysis, $3 \mu \mathrm{g}$ of total RNA was converted into cDNA using M-MLV Reverse Transcriptase (Invitrogen). The ST8SIA mRNA was quantified using a SYBR Green Quantitative Real-time PCR mix (TaKaRa, Otsu, and Shiga, Japan) and normalized to GAPDH (glyceraldehyde-3-phosphate dehydrogenase). The sequences of the upstream and downstream primers were as follows: 5'-TAC TCT CTC TTC CCA CAG G-3'; 5'-GAC AAA GGA GGG AGA TTG C-3' for ST8SIA1; 5'-GTG GTC TTC CTC ATC TTC G-3'; 5'-GAG GAG CCG TTT ATT ACA AC-3' for ST8SIA2; 5'-ATT CTC TCA CCC AGG AAC TC-3' and 5'-CAA TCC GAA CAC TAT TCT TG-3' for ST8SIA3; 5'-CAA GAA CTG AGG AGC ACC-3' and 5'-TTT CCA ACC TTC TAC ATT GTG3' for ST8SIA4; 5'-CCT TTG CCT TGG TGA CCT-3' and 5'-CAT GGA CAG CAC CTT CAC T-3' for ST8SIA5; 5'-CGG CAA GCA GAA GAA TAT G-3' and 5'-GCT TTC CAC CTC GTA ACT C-3' for ST8SIA6; 5'-CTC CTC CAC CTT TGA CGC TG-3'; 5'-TCC TCT TGT GCT CTT GCT GG-3' for GAPDH. The expression level of the target genes was determined relative to GAPDH expression and calculated using the $2^{-\Delta \Delta \mathrm{CT}}$ method.

The expression of $\mathrm{miR}-146 \mathrm{a} / \mathrm{b}$ was determined using a mirVana Quantitative Reverse Transcription Polymerase Chain Reaction (qRT-PCR) microRNA Detection Kit according to the manufacturer's protocol (Ambion Inc., Austin, TX, USA) and normalized relative to U6-small nuclear RNA using the $2^{-\Delta \Delta \mathrm{CT}}$ method. For reverse transcription, $5 \mu \mathrm{g}$ of total RNA was converted to cDNA using a TaqMan MicroRNA Reverse Transcription Kit (Fermentas) according to the manufacturer's protocol. The resulting cDNA was diluted 1:10 and used for PCR with $4 \mu \mathrm{L}$ of miR-146a/b or U6 TaqMan primers and SYBR Green/Fluorescein qPCR Master Mix (Fermentas) with the ABI PRISM 7900HT Sequence Detection System (Applied Biosystems, Foster City, CA, USA). Next, 10 ng of total RNA was reverse transcribed using a HighCapacity cDNA Archive Kit (Applied Biosystems Inc., Foster City, CA) and then amplified on a ABI 7500 RealTime PCR System (Applied Biosystems Inc., Foster City,
CA). Real-time PCR was performed for 2 min at $95^{\circ} \mathrm{C}$ and then for 40 cycles of amplification for $20 \mathrm{~s}$ at $95^{\circ} \mathrm{C}$ and 1 $\min$ at $60^{\circ} \mathrm{C}$.

\section{Western blot analysis}

Whole cell proteins were electrophoresed under reducing conditions on a $10 \%$ polyacrylamide gel. The separated proteins were transferred to a polyvinylidene difluoride membrane. After the membranes were blocked with 5\% skim milk in PBS containing $0.1 \%$ Tween 20 (PBST), they were incubated with the appropriate antibody (1:1000; Abcam, Cambridge, UK) overnight at $4{ }^{\circ} \mathrm{C}$ and then incubated with peroxidase-conjugated anti-rabbit IgG (1:10000; GE Healthcare UK Ltd., Little Chalfont, U.K.). GAPDH was used as a control. Band intensity was evaluated using an ECL Western Blotting Substrate Kit (Amersham Biosciences, Buckinghamshire, UK) according to the manufacturer's protocol. The bands were analysed using LabWorks (ver4.6, UVP, BioImaging Systems).

\section{Transfection and luciferase activity assay}

Mimics, antagomirs and negative control oligonucleotides for hsa-miR-146a/b were obtained from RiboBio Co., Ltd. (Shanghai, China). Plasmids containing WT Luc-ST8SIA4, mutant Luc-ST8SIA4, and lenti-miR$146 \mathrm{a} / \mathrm{b}$ were synthesized. FTC cells were transfected using Lipofectamine 2000 reagent (Invitrogen, Carlsbad, CA) according to the manufacturer's instruction. Luciferase activity was measured $48 \mathrm{~h}$ after transfection using the Dual-Luciferase Reporter Assay System (Promega). Firefly luciferase activity was normalized to Renilla luciferase activity for each sample. The mean of the results from the cells transfected with the miR-control was set at 1.0. The data are presented as the mean value $\pm \mathrm{SD}$ for three repeated experiments.

\section{Downregulation of ST8SIA4 by RNAi}

FTC-133 cells were incubated in the appropriate antibiotic-free medium with $10 \%$ foetal bovine serum. The cells were then transferred to a 6-well plate prior to incubation in a $\mathrm{CO}_{2}$ incubator at $37^{\circ} \mathrm{C}$ to obtain $60-80 \%$ confluency. ST8SIA4 shRNA was mixed with Lipofectamine 2000. The cells were then harvested for further analysis. The transfected cells were cultured at $37^{\circ} \mathrm{C}$ for $6 \mathrm{~h}$ and then incubated with complete medium for an additional $24 \mathrm{~h}$. Thereafter, the cells were harvested for further examination.

\section{Overexpression of ST8SIA4}

The human ST8SIA4 coding sequences obtained from TaKaRa (Dalian, China) were inserted into the pEGFP-N2 vector (Invitrogen, Carlsbad, CA) at the EcoRI and XhoI sites. The cells were transfected with $5 \mu \mathrm{g}$ of 
the target gene expression vector or empty vector (EV) in $100 \mathrm{~mm}$ dishes using PolyFect Transfection Reagent (Qiagen, Valencia, CA) according to the manufacturer's instructions. After 4 weeks of screening, the cell lines stably expressing ST8SIA4 (overexpression of ST8SIA4 in FTC238 cells) and the corresponding empty vector (FTC-238/ mock) were established and verified using western blotting.

\section{Cell proliferation assay (CCK8 assay)}

For the proliferation assay, the transfected cells and negative control (NC) cells were seeded at $5 \times 10^{3}$ cells/ well in 96-well plates and incubated at $37^{\circ} \mathrm{C}$ for 4 days. A $10 \mu \mathrm{l}$ aliquot of Cell Counting Kit- 8 reagent (Dojindo, Japan) was added to the cells. Following incubation for $3 \mathrm{~h}$, absorbance was measured at $450 \mathrm{~nm}$ using a spectrophotometer (Bio-Rad, USA).

\section{In vitro invasion assay}

Cell invasion in vitro was demonstrated using 24well Transwell units (Corning, NY, USA) with a $8 \mu \mathrm{m}$ pore size polycarbonate filter coated with extracellular matrix gel (EC Matrix gel) (Millipore Chemicon, MA, USA) to form a continuous thin layer. The cells $\left(3 \times 10^{5}\right)$ were harvested in serum-free medium containing $0.1 \% \mathrm{BSA}$ and then added to the upper chamber. The lower chamber contained $500 \mu \mathrm{l}$ DMEM. The cells were incubated for $24 \mathrm{~h}$ at $37^{\circ} \mathrm{C}$ in an incubator containing $5 \% \mathrm{CO}_{2}$. After incubation, the cells on the upper surface of the filter were completely removed by wiping with a cotton swab. The filters were then fixed in methanol and stained with Wright-Giemsa stain. Cells that had invaded the Matrigel and reached the lower surface of the filter were counted using a light microscope at a magnification of $40 \times$.

\section{Wound-healing assay}

For the wound-healing assays, confluent monolayers of FTC-133 and FTC-238 cells were treated with $2 \mu \mathrm{g} / \mathrm{ml}$ of mitomycin for $2 \mathrm{~h}$ (Sigma-Aldrich). The transfected cells were seeded onto 6 -well plates at $1 \times 10^{5}$ cells $/ 1$ and then cultivated in DMEM to maintain adherent cell growth for $6 \mathrm{~h}$. Scratching (wounding) was performed using a $10 \mu \mathrm{l}$ Eppendorf tip. The cells were cultured in 5\% $\mathrm{CO}_{2}$ at $37^{\circ} \mathrm{C}$ for $24 \mathrm{~h}$ after they were washed in serumfree medium 3 times. Images were taken to determine the number of migrating cells between the scratches using Image-Pro Plus 6.0 software. The mean values and standard deviations were calculated for the intra-group comparisons. The experiment was repeated 3 times.

\section{Colony formation assays}

The transfected cells were seeded in 6-well (100 cells/well) culture plates (BD Biosciences). The cells were incubated at $37^{\circ} \mathrm{C}$ with $5 \% \mathrm{CO}_{2}$ for $7-12$ days until visible colony formation was observed in the dish. Subsequently, the culture medium was removed, and the wells were washed twice with phosphate-buffered saline (PBS). The colonies were fixed with $10 \%$ methanol for $20 \mathrm{~min}$, dried and stained with $0.1 \%$ crystal violet solution for $15 \mathrm{~min}$. Each plate was then washed three times with $9 \%$ sodium chloride solution. Cell colonies with $>50$ cells were counted and imaged.

\section{In vivo tumourigenicity assay}

Athymic nude mice (5-week-old) were obtained from the Animal Facility of Dalian Medical University and provided with sterilized food and water. Approximately $1 \times 10^{7}$ cells were injected subcutaneously into the right flank of each nude mouse. After palpable tumours were identified (approximately 4 weeks after tumour cell inoculation), the mice were sacrificed, and their tumours were isolated and weighed.

\section{Statistical analysis}

The data are expressed as the mean \pm standard deviation (SD). SPSS 17.0 software was used for the statistical analysis, and Student's $t$-test was used to determine the significance of differences among the examined groups. Normally distributed data were compared using a one-way ANOVA followed by the Student-Newman-Keuls test. A value of $p<0.05$ was considered statistically significant.

\section{ACKNOWLEDGMENTS AND FUNDING}

This work was supported by a grant from the Province Director Fund of the Natural Science Foundation of Liaoning (No.2015020252), the Science and Technology Plan Projects of the Dalian City Director Fund (No.2015E12SF148) and The Key Disciplines Construction Program of The Second Hospital of Dalian Medical University.

\section{CONFLICTS OF INTEREST}

The authors declare no conflicts of interest.

\section{REFERENCES}

1. Kroll TG. Molecular events in follicular thyroid tumors. Cancer Treat Res. 2004; 122:85-105.

2. Raman P, Koenig RJ. Pax-8-PPAR-gamma fusion protein in thyroid carcinoma. Nat Rev Endocrinol. 2014; 10:616-623.

3. Rothhut B, Ghoneim C, Antonicelli F, SoulaRothhut M. Epidermal growth factor stimulates matrix metalloproteinase-9 expression and invasion in human follicular thyroid carcinoma cells through focal adhesion kinase. Biochimie. 2007; 89:613-624. 
4. Dettmer $M$, Perren A, Moch H, Komminoth $P$, Nikiforov YE, Nikiforova MN. Comprehensive microRNA expression profiling identifies novel markers in follicular variant of papillary thyroid carcinoma. Thyroidology. 2013; 23:1383-1389.

5. Bhargav PR, Mishra A, Agarwal G, Agarwal A, Pradhan PK, Gambhir S, Verma AK, Mishra SK. Long-term outcome of differentiated thyroid carcinoma: experience in a developing country. World J Surg. 2010; 34:40-47.

6. Takashima S, Matsumoto $\mathrm{T}$, Tsujimoto M, Tsuji S. Effects of amino acid substitutions in the sialylmotifs on molecular expression and enzymatic activities of alpha2,8sialyltransferases ST8Sia-I and ST8Sia-VI. Glycobiology. 2013; 23:603-612.

7. Dennis J, Waller C, Timpl R, Schirrmacher V. Surface sialic acid reduces attachment of metastatic tumour cells to collagen type IV and fibronectin. Nature. 1982; 300:274-276.

8. Yogeeswaran G, Salk PL. Metastatic potential is positively correlated with cell surface sialylation of cultured murine tumor cell lines. Science. 1981; 212:1514-1516.

9. Harvey BE, Toth CA, Wagner HE, Steele GD, Jr, Thomas P. Sialyltransferase activity and hepatic tumor growth in a nude mouse model of colorectal cancer metastases. Cancer Res. 1992; 52:1775-1779.

10. Wang L, Liu Y, Wu L, Sun XL. Sialyltransferase inhibition and recent advances. Biochim Biophys Acta. 2016; 1864:143-153.

11. Ma H, Zhou H, Song X, Shi S, Zhang J, Jia L. Modification of sialylation is associated with multidrug resistance in human acute myeloid leukemia. Oncogene. 2015; 34:726-740.

12. Zhao Y, Li Y, Ma H, Dong W, Zhou H, Song X, Zhang J, Jia L. Modification of sialylation mediates the invasive properties and chemosensitivity of human hepatocellular carcinoma. Mol Cell Proteomics. 2014; 13:520-536.

13. Alvarez-Garcia I, Miska EA. MicroRNA functions in animal development and human disease. Development. 2005; 132:4653-4662.

14. Gibb EA, Brown CJ, Lam WL. The functional role of long noncoding RNA in human carcinomas. Mol Cancer. 2011; 10:38.

15. Aalaei-Andabili SH, Fabbri M, Rezaei N. Reciprocal effects of toll-like receptors and miRNAs on biological processes in human health and disease: a systematic review. Immunotherapy. 2013; 5:1127-1142.

16. Ma Y, Qin H, Cui Y. MiR-34a targets GAS1 to promote cell proliferation and inhibit apoptosis in papillary thyroid carcinoma via PI3K/Akt/Bad pathway. Biochem Biophys Res Commun. 2013; 441:958-963.

17. Xue L, Su D, Li D, Gao W, Yuan R, Pang W. miR-200 regulates epithelial-mesenchymal transition in anaplastic thyroid Cancer via EGF/EGFR signaling. Cell Biochem Biophys. 2015; 72:185-190.

18. Saji M, Ringel MD. The PI3K-Akt-mTOR pathway in initiation and progression of thyroid tumors. Mol Cell Endocrinol. 2010; 321:20-28.
19. Kim SH, Kang JG, Kim CS, Ihm SH, Choi MG, Yoo HJ, Lee SJ. Synergistic cytotoxicity of BIIB021 with triptolide through suppression of PI3K/Akt/mTOR and NF- $\mathrm{KB}$ signal pathways in thyroid carcinoma cells. Biomed Pharmacother. 2016; 83:22-32.

20. Manfredi GI, Dicitore A, Gaudenzi G, Caraglia M, Persani L, Vitale G. PI3K/Akt/mTOR signaling in medullary thyroid cancer: a promising molecular target for cancer therapy. Endocrine. 2015; 48:363-370.

21. Baik SH, Lee J, Lee YS, Jang JY, Kim CW. ANT2 shRNA downregulates miR-19a and miR-96 through the PI3K/Akt pathway and suppresses tumor growth in hepatocellular carcinoma cells. Exp Mol Med. 2016; 48:e222.

22. Matà R, Palladino C, Nicolosi ML, Lo Presti AR, Malaguarnera R, Ragusa M, Sciortino D, Morrione A, Maggiolini M, Vella V, Belfiore A. IGF-I induces upregulation of DDR1 collagen receptor in breast cancer cells by suppressing MIR-199a-5p through the PI3K/AKT pathway. Oncotarget. 2016; 7:7683-7700. doi: 10.18632/ oncotarget.6524.

23. Riquelme I, Tapia O, Leal P, Sandoval A, Varga MG, Letelier P, Buchegger K, Bizama C, Espinoza JA, Peek RM, Araya JC, Roa JC. miR-101-2, miR-125b-2 and miR-451a act as potential tumor suppressors in gastric cancer through regulation of the PI3K/AKT/mTOR pathway. Cell Oncol (Dordr). 2016;39; 39:23-33.

24. Deng X, Wu B, Xiao K, Kang J, Xie J, Zhang X, Fan Y. MiR-146b-5p promotes metastasis and induces epithelialmesenchymal transition in thyroid cancer by targeting ZNRF3. Cell Physiol Biochem. 2015; 35:71-82.

25. Czajka AA, Wójcicka A, Kubiak A, Kotlarek M, BakułaZalewska E, Koperski Ł, Wiechno W, Jażdżewski K. Family of microRNA-146 regulates RARbeta in papillary thyroid carcinoma. PLOS ONE. 2016; 11:e0151968.

26. Sun M, Fang S, Li W, Li C, Wang L, Wang F, Wang Y. Associations of miR-146a and miR-146b expression and clinical characteristics in papillary thyroid carcinoma. Cancer Biomark. 2015; 15:33-40.

27. Ortiz-Soto ME, Seibel J. Expression of functional human sialyltransferases ST3Gall and ST6Gall in Escherichia coli. PLOS ONE. 2016; 11:e0155410.

28. Bork K, Horstkorte R, Weidemann W. Increasing the sialylation of therapeutic glycoproteins: the potential of the sialic acid biosynthetic pathway. J Pharm Sci. 2009; 98:3499-3508.

29. Harduin-Lepers A, Krzewinski-Recchi MA, Colomb F, Foulquier F, Groux-Degroote S, Delannoy P. Sialyltransferases functions in cancers. Front Biosci (Elite Ed). 2012; 4:499-515.

30. He H, Jazdzewski K, Li W, Liyanarachchi S, Nagy R, Volinia S, Calin GA, Liu CG, Franssila K, Suster S, Kloos RT, Croce CM, de la Chapelle A. The role of microRNA genes in papillary thyroid carcinoma. Proc Natl Acad Sci USA. 2005; 102:19075-19080.

31. Zhang Z, Liu ZB, Ren WM, Ye XG, Zhang YY. The miR200 family regulates the epithelial-mesenchymal transition 
induced by EGF/EGFR in anaplastic thyroid cancer cells. Int J Mol Med. 2012; 30:856-862.

32. Geraldo MV, Yamashita AS, Kimura ET. MicroRNA miR$146 \mathrm{~b}-5 \mathrm{p}$ regulates signal transduction of TGF-beta by repressing SMAD4 in thyroid cancer. Oncogene. 2012; 31:1910-1922.

33. Fassina A, Cappellesso R, Simonato F, Siri M, Ventura L, Tosato F, Busund LT, Pelizzo MR, Fassan M. A 4-microRNA signature can discriminate primary lymphomas from anaplastic carcinomas in thyroid cytology smears. Cancer Cytopathol. 2014; 122:274-281.

34. Krek A, Grün D, Poy MN, Wolf R, Rosenberg L, Epstein EJ, MacMenamin P, da Piedade I, Gunsalus KC, Stoffel M, Rajewsky N. Combinatorial microRNA target predictions. Nat Genet. 2005; 37:495-500.

35. Marino M, Cirello V, Gnarini V, Colombo C, Pignatti E, Casarini L, Diazzi C, Rochira V, Cioni K, Madeo B,
Carani C, Simoni M, Fugazzola L. Are pre-miR-146a and PTTG1 associated with papillary thyroid cancer? Endocr Connect. 2013; 2:178-185.

36. Vella V, Puppin C, Damante G, Vigneri R, Sanfilippo M, Vigneri P, Tell G, Frasca F. DeltaNp73alpha inhibits PTEN expression in thyroid cancer cells. Int J Cancer. 2009; 124:2539-2548.

37. Smith JR, Marqusee E, Webb S, Nose V, Fishman SJ, Shamberger RC, Frates MC, Huang SA. Thyroid nodules and cancer in children with PTEN hamartoma tumor syndrome. J Clin Endocrinol Metab. 2011; 96:34-37.

38. Liaw D, Marsh DJ, Li J, Dahia PL, Wang SI, Zheng Z, Bose S, Call KM, Tsou HC, Peacocke M, Eng C, Parsons R. Germline mutations of the PTEN gene in Cowden disease, an inherited breast and thyroid cancer syndrome. Nat Genet. 1997; 16:64-67. 